\title{
Plant regeneration of non-toxic Jatropha curcas - impacts of plant growth regulators, source and type of explants
}

\author{
Nitish Kumar • K. G. Vijay Anand • Muppala P. Reddy
}

Received: 9 February 2010 /Accepted: 18 December 2010 /Published online: 28 January 2011

(C) Society for Plant Biochemistry and Biotechnology 2011

\begin{abstract}
Jatropha curcas is an oil bearing species with multiple uses and considerable economic potential as a biofuel plant, however, oil and deoiled cake are toxic. A non-toxic variety of $J$. curcas is reported from Mexico. The present investigation explores the effects of different plant growth regulators (PGRs) viz. 6-benzyl aminopurine (BAP) or thidiazuron (TDZ) individually and in combination with indole-3-butyric acid (IBA), on regeneration from in vitro and field-grown mature leaf explants, in vitro and glasshousegrown seedlings cotyledonary leaf explants of non-toxic $J$. curcas. In all the tested parameters maximum regeneration efficiency $(81.07 \%)$ and the number of shoot buds per explants (20.17) was observed on $9.08 \mu \mathrm{M}$ TDZ containing Murashige and Skoog's (MS) medium from in vitro cotyledonary leaf explants. The regenerated shoot buds were transferred to MS medium containing $10 \mu \mathrm{M}$ kinetin $(\mathrm{Kn})$,
\end{abstract}

N. Kumar $(\bowtie) \cdot$ K. G. Vijay Anand $\cdot$ M. P. Reddy

Discipline of Wasteland Research, Central Salt \& Marine

Chemicals Research Institute

(Council of Scientific and Industrial Research),

Bhavnagar, Gujarat 364002, India

e-mail: nitishbt1@rediffmail.com

N. Kunar

e-mail: nitish@cub.ac.in

Present Address:

N. Kumar

Centre for Biotechnology, School of Earth, Biological and

Environmental Science, Central University of Bihar,

Patna 800014 Bihar, India

Present Address:

M. P. Reddy

Plant Stress Genomics Research Center,

King Abdullah University of Science and Technology,

Thuwal 23955-6900, Kingdom of Saudi Arabia

email: reddymuppalareddy@gmail.com
4.5 $\mu \mathrm{M}$ BAP and $5.5 \mu \mathrm{M} \alpha$-naphthaleneacetic acid (NAA) for shoot proliferation. The proliferated shoots could be elongated on MS medium supplemented with $2.25 \mu \mathrm{M}$ BAP and $8.5 \mu \mathrm{M}$ IAA. Rooting was achieved when the basal cut end of elongated shoots were dipped in half strength MS liquid medium containing different concentrations and combinations of IBA, IAA and NAA for four days followed by transfer to growth regulators free half strength MS medium supplemented $0.25 \mathrm{mg} / \mathrm{l}$ activated charcoal. The rooted plants could be established in soil with more than $90 \%$ survival rate.

Keywords Non-toxic Jatropha curcas · Leaf · Plant growth regulator $\cdot$ Regeneration
Abbreviations
BAP 6-Benzylaminopurine
IAA Indole-3-acetic acid
IBA Indole-3-butyric acid
Kn Kinetin
MS Murashige and Skoog
NAA Naphthaleneacetic acid
TDZ Thidiazuron

\section{Introduction}

Jatropha curcas L. is a perennial deciduous, multipurpose shrub belonging to the family Euphorbiaceae, native to Central America region and later distributed in many parts of the tropic and subtropic regions of the world. Primarily $J$. curcas plant was used for its medicinal values, however, recently received tremendous attention for its seed oil that can be converted into biodiesel and is considered to be a universally acceptable as an energy crop and alternative to conventional fossil fuels (Takeda 1982). However, the 
seeds are toxic and the pressed cake is not useful as fodder despite having the best protein composition (Makkar et al. 1998). A non-toxic variety has been reported from the Papantla region of Veracruz State in Mexico, suitable for human consumption and its innocuous nature was established using fish and rats as experimental models (Makkar and Becker 1997). Cultivation of the non-toxic variety of $J$. curcas assumes utmost importance as it can provide edible oil and seed cake for livestock and gives value addition to the crop. To meet the large-scale demand and ensure easy supply of this elite material, there is a need to develop mass multiplication techniques. Attempts have been made to regenerate toxic variety of $J$. curcas (Sujatha and Mukta 1996; Rajore and Batra 2007; Jha et al. 2007; Deore and Johnson 2008; Misra et al. 2010; Kumar and Reddy 2010; Kumar et al. 2010a). However, there is very few reports on non-toxic variety of $J$. curcas where regeneration was obtained from leaf with the presence of intermediary callus (Sujatha et al. 2005) and petiole (Kumar et al. 2010b, 2011). It has also been reported that regeneration in $J$. curcas is highly genotype dependent (da Camara Machado et al. 1997; Kumar 2008; Kumar and Reddy 2010; Kumar et al. 2010a). The objective of this study was to develop a direct plant regeneration method from mature and cotyledonary leaf explants of non-toxic $J$. curcas for subsequent use in mass multiplication and genetic improvement. As far as we are aware, this is the first report of direct regeneration of shoot buds from leaf explants of non-toxic J. curcas. This study also compared the impacts of PGRs, source and type of explants on regeneration.

\section{Materials and methods}

\section{Plant material}

In vitro shoot cultures of non-toxic variety of $J$. curcas were established by culturing nodal explants collected from 3-4 year old plants. The excised nodal explants of 3-4 cm with axillary buds were surface sterilized with $0.1 \%$ mercuric chloride $\left(\mathrm{HgCl}_{2}\right)$ for $15 \mathrm{~min}$ and rinsed five times in sterile distilled water. The sterilized nodal explants were cultured on MS solid medium (Murashige and Skoog 1962) supplemented with $27 \mu \mathrm{M}$ 6-benzyl aminopurine (BAP) and $5 \mu \mathrm{M}$ indole-3-butyric acid (IBA) for the sprouting of axillary buds and formation of shoots. After 4 weeks of culture, mature leaves were collected from axillary shoots and used as in vitro mature leaf explants. For field-grown mature leaf explants, leaves were collected, which are close to apical buds from 3-4 year old plants, were sterilized with $0.1 \%$ mercuric chloride $\left(\mathrm{HgCl}_{2}\right)$ for 7 min separately.

For in vitro cotyledonary leaf explant, seedcoats of seeds were removed and then surface sterilized by $0.1 \%$ mercuric chloride $\left(\mathrm{HgCl}_{2}\right)$ for $15 \mathrm{~min}$ and rinsed five times in sterile distilled water. The sterilized seeds were germinated on hormone free MS liquid medium supplemented with $3 \%$ sucrose with the support of filter paper boat. After 2 week of germination, cotyledonary leaves were collected from germinated seedlings and used as in vitro cotyledonary leaf explants. For glasshouse-grown seedlings cotyledonary leaf explants, seedlings were raised in the nursery and cotyledonary leaves were collected from 2 week old seedlings, and sterilized by $0.1 \%$ mercuric chloride $\left(\mathrm{HgCl}_{2}\right)$ for 4 min and rinsed five times in sterile distilled water.

\section{Regeneration of shoot bud}

The in vitro and field-grown mature leaf explants, in vitro and glasshouse-grown seedlings cotyledonary leaf explants were cultured on MS medium supplemented with $3 \%$ sucrose and various concentrations of thidiazuron (TDZ) or BAP individually and in combination with $5 \mu \mathrm{M}$ indole-3-butyric acid (IBA) to find the optimum culture medium for regeneration of shoot bud (Table 1) (Reddy et al. 2008; Kumar and Reddy 2010; Kumar et al. 2010a). Leaf explants were inoculated on to the medium in $200 \times 38 \mathrm{~mm}$ culture tubes (Borosil, India). The percentage of regeneration of shoot buds and the number of shoot buds per explant were recorded after 6 weeks of culture.

Shoot proliferation and elongation from regenerated shoot buds

The regenerated shoot buds were transferred on to MS medium supplemented with $3 \%$ sucrose, $10 \mu \mathrm{M}$ kinetin (Kn), $4.5 \mu \mathrm{M}$ BAP and $5.5 \mu \mathrm{M} \alpha$-naphthaleneacetic acid (NAA) for 4 weeks for shoot proliferation (Reddy et al. 2008; Kumar and Reddy 2010; Kumar et al. 2010a). Shoots were individually separated and further tested for their elongation on MS medium supplemented with 3\% sucrose and different concentrations and combinations of BAP, indole-3-acetic acid (IAA), NAA and IBA (Table 3). The length of the elongated shoots was recorded after 6 weeks of culture.

\section{Rooting and acclimatization}

Green and healthy elongated shoots with three to four leaves were excised and cultured on half strength MS liquid medium supplemented with different concentrations and combinations of auxins viz. IBA, IAA and NAA with the support of Whatman No. 44 filter paper for 4 days (Fig. 1i) (Reddy et al. 2008; Kumar and Reddy 2010; Kumar et al. 2010a). This auxins treated elongated shoots were trans- 
Table 1 Effect of different plant growth regulators (PGRs), type of explants $(\mathrm{T})$ [mature or cotyledonary leaf] and source (S) [in vitro or field/glasshousegrown] on the percentage of regeneration of shoot buds of non-toxic $J$. curcas after 6 weeks
BAP, 6-benzylaminopurine; IBA, indole-3-butyric acid TDZ, thidiazuron. Values represent means \pm SE of 25 explants per treatment in three repeated experiments. ${ }^{*}$ Significant at $5 \%$ probability level ( $F$ test). NS, not significant

\begin{tabular}{|c|c|c|c|c|c|c|}
\hline \multicolumn{3}{|c|}{ PGRs $(\mu \mathrm{M})$} & \multicolumn{4}{|c|}{ Regeneration of shoot buds (\%) } \\
\hline \multirow[t]{2}{*}{ TDZ } & \multirow[t]{2}{*}{ BAP } & \multirow[t]{2}{*}{ IBA } & \multicolumn{2}{|c|}{ Mature leaf expant } & \multicolumn{2}{|c|}{ Cotyledonary leaf expants } \\
\hline & & & In vitro & Field-grown & In vitro & Glasshouse-grown \\
\hline 0.22 & 0 & 0 & $23.34 \pm 2.32$ & $11.14 \pm 1.98$ & $43.23 \pm 4.52$ & $41.10 \pm 4.98$ \\
\hline 0.45 & 0 & 0 & $34.61 \pm 3.41$ & $15.80 \pm 2.08$ & $54.09 \pm 5.51$ & $51.98 \pm 5.28$ \\
\hline 0.90 & 0 & 0 & $44.19 \pm 4.52$ & $18.61 \pm 2.60$ & $64.06 \pm 6.51$ & $61.11 \pm 6.70$ \\
\hline 2.27 & 0 & 0 & $63.68 \pm 5.14$ & $31.22 \pm 3.17$ & $73.34 \pm 7.04$ & $71.12 \pm 7.27$ \\
\hline 4.54 & 0 & 0 & $67.51 \pm 6.16$ & $33.82 \pm 3.96$ & $77.90 \pm 7.16$ & $75.72 \pm 7.76$ \\
\hline 9.08 & 0 & 0 & $68.36 \pm 6.26$ & $34.83 \pm 3.76$ & $81.07 \pm 8.26$ & $79.11 \pm 7.66$ \\
\hline 0.22 & 0 & 5 & $19.31 \pm 1.72$ & $10.13 \pm 1.01$ & $39.11 \pm 3.42$ & $37.87 \pm 3.61$ \\
\hline 0.45 & 0 & 5 & $31.67 \pm 3.01$ & $13.56 \pm 2.07$ & $51.07 \pm 5.01$ & $49.76 \pm 4.67$ \\
\hline 0.90 & 0 & 5 & $41.61 \pm 4.41$ & $16.67 \pm 2.05$ & $61.11 \pm 6.41$ & $59.17 \pm 5.65$ \\
\hline 2.27 & 0 & 5 & $59.67 \pm 5.12$ & $29.21 \pm 3.56$ & $69.04 \pm 6.08$ & $65.11 \pm 6.16$ \\
\hline 4.54 & 0 & 5 & $63.65 \pm 5.06$ & $31.81 \pm 3.45$ & $71.75 \pm 7.06$ & $66.11 \pm 6.05$ \\
\hline 9.08 & 0 & 5 & $67.66 \pm 6.01$ & $31.81 \pm 3.87$ & $74.96 \pm 7.01$ & $66.11 \pm 6.57$ \\
\hline 0 & 13.5 & 0 & $14.11 \pm 1.46$ & $7.12 \pm 1.61$ & $25.23 \pm 2.31$ & $23.11 \pm 2.51$ \\
\hline 0 & 27.0 & 0 & $26.01 \pm 2.69$ & $11.56 \pm 1.91$ & $38.81 \pm 2.99$ & $38.16 \pm 3.41$ \\
\hline 0 & 40.5 & 0 & $35.51 \pm 3.51$ & $13.66 \pm 2.05$ & $44.61 \pm 4.01$ & $43.36 \pm 4.45$ \\
\hline 0 & 54.0 & 0 & $49.67 \pm 4.12$ & $25.11 \pm 2.17$ & $51.07 \pm 5.02$ & $48.98 \pm 4.11$ \\
\hline 0 & 13.5 & 5 & $13.92 \pm 1.31$ & $7.02 \pm 1.51$ & $23.12 \pm 2.41$ & $22.12 \pm 2.50$ \\
\hline 0 & 27.0 & 5 & $26.00 \pm 2.61$ & $11.51 \pm 1.31$ & $36.87 \pm 3.81$ & $35.11 \pm 3.31$ \\
\hline 0 & 40.5 & 5 & $34.91 \pm 3.41$ & $13.36 \pm 1.49$ & $41.11 \pm 4.11$ & $40.26 \pm 4.40$ \\
\hline 0 & 54.0 & 5 & $48.91 \pm 4.82$ & $25.01 \pm 2.13$ & $48.81 \pm 4.12$ & $46.11 \pm 4.03$ \\
\hline \multicolumn{7}{|c|}{ ANOVA summary table } \\
\hline Source & & $\mathrm{df}$ & MS & $\mathrm{F}$ & & \\
\hline S & & 1 & 113.75 & $21.52^{*}$ & & \\
\hline $\mathrm{T}$ & & 1 & 298.82 & $41.05^{*}$ & & \\
\hline $\mathrm{S} \times \mathrm{T}$ & & 1 & 72.85 & $7.01^{*}$ & & \\
\hline PGRs & & 19 & 31482 & $1961.82 *$ & & \\
\hline $\mathrm{S} \times \mathrm{PC}$ & & 19 & 92.72 & $11.18^{*}$ & & \\
\hline $\mathrm{T} \times \mathrm{PC}$ & & 19 & 93.97 & $9.41^{*}$ & & \\
\hline $\mathrm{S} \times \mathrm{T}$ & GRs & 19 & 21.88 & $1.61 \mathrm{NS}$ & & \\
\hline Error & & 160 & 6.11 & & & \\
\hline Total & & 239 & & & & \\
\hline
\end{tabular}

ferred to growth regulators free half strength MS solid medium supplemented with $0.25 \mathrm{mg} / \mathrm{L}$ activated charcoal. The percent root induction was recorded after 4 weeks. Rooted shoots were carefully taken out of the medium and washed thoroughly in sterilized distilled water to remove medium attached to the roots. The plants were transferred to plastic bags containing sterilized sand and soil in the ratio of $1: 1$ and wetted with $0.02 \% \mathrm{w} / \mathrm{v}$ carbendazim and covered with transparent plastic bags to maintain humidity. After 3-4 weeks, the established plants were transplanted to polythene bags containing garden soil and farmyard manure and transferred to a green house for further growth and the percentage of surviving plants were recorded after 6-8 weeks.

Culture conditions and data analysis

Uniform culture conditions were applied in all experiments. The $\mathrm{pH}$ of the medium was adjusted to 5.7 using $1 \mathrm{~N} \mathrm{KOH}$ or $\mathrm{HCl}$, prior to autoclaving at $1.05 \mathrm{~kg} / \mathrm{cm}^{2}$ pressure at $121^{\circ} \mathrm{C}$ for $20 \mathrm{~min}$. The cultures were maintained at $25 \pm 2^{\circ} \mathrm{C}$ under a $16 \mathrm{~h}$ photoperiod with light intensity of $35-40 \mu_{\text {molm }}^{-2} \mathrm{~s}^{-1}$ (cool white fluorescent tubes). 
Fig. 1 Plant regeneration from leaf explants of non-toxic Jatropha curcas. Plant regeneration from $\mathbf{a}$ in vitro mature leaf explant (bar $5 \mathrm{~mm}$ ), b Fieldgrown mature leaf explant (bar $5 \mathrm{~mm}$ ), $\mathbf{c}$ in vitro cotyledonary leaf explant (bar $5 \mathrm{~mm}$ ) and $\mathbf{d}$ Glasshouse-grown cotyledonary leaf explants (bar $5 \mathrm{~mm}$ ) on MS medium with $2.27 \mu \mathrm{M}$ thidiazuron (TDZ) after 6 weeks. e Shoot proliferation of regenerated shoot buds on MS medium with $10 \mu \mathrm{M}$ kinetin $(\mathrm{Kn})+$ $4.50 \mu \mathrm{M}$ 6-benzyl aminopurine $(\mathrm{BAP})+5.50 \mu \mathrm{M} \alpha-$ naphthaleneacetic acid (NAA) after 4 weeks (bar $75 \mathrm{~mm}$ ). f Elongation of proliferated shoot on MS medium with $2.25 \mu \mathrm{M}$ $\mathrm{BAP}+8.5 \mu \mathrm{M}$ indole-3-acetic acid (IAA) after 6 weeks (bar $5 \mathrm{~mm})$. g Elongation of proliferated shoot on MS medium with $2.25 \mu \mathrm{M}$ BAP $+2.5 \mu \mathrm{M}$ indole-3-butyric acid (IBA) after 6 weeks (bar $5 \mathrm{~mm}$; arrow indicate proliferation of axillary buds). h Elongation of proliferated shoot on MS medium with $2.25 \mu \mathrm{M} \mathrm{BAP}+8.25 \mu \mathrm{M}$ NAA after 6 weeks (bar $5 \mathrm{~mm}$; arrow indicate formation of callus at the base). i Elongated shoot cultured on half strength basal MS liquid medium supplemented with $15 \mu \mathrm{M}$ IBA + $5.7 \mu \mathrm{M} \mathrm{IAA}+5.5 \mu \mathrm{M}$ NAA for root induction (bar $1 \mathrm{~mm}$ ). $\mathbf{j}$ Development of roots at the base of auxins treated elongated shoot on half strength basal MS medium with $0.25 \mathrm{mg} / 1$ activated charcoal after 4 weeks (bar $1 \mathrm{~mm}) . \mathbf{k}$ Regenerated plant in polythene bags after 2 weeks (bar $100 \mathrm{~mm}$ )
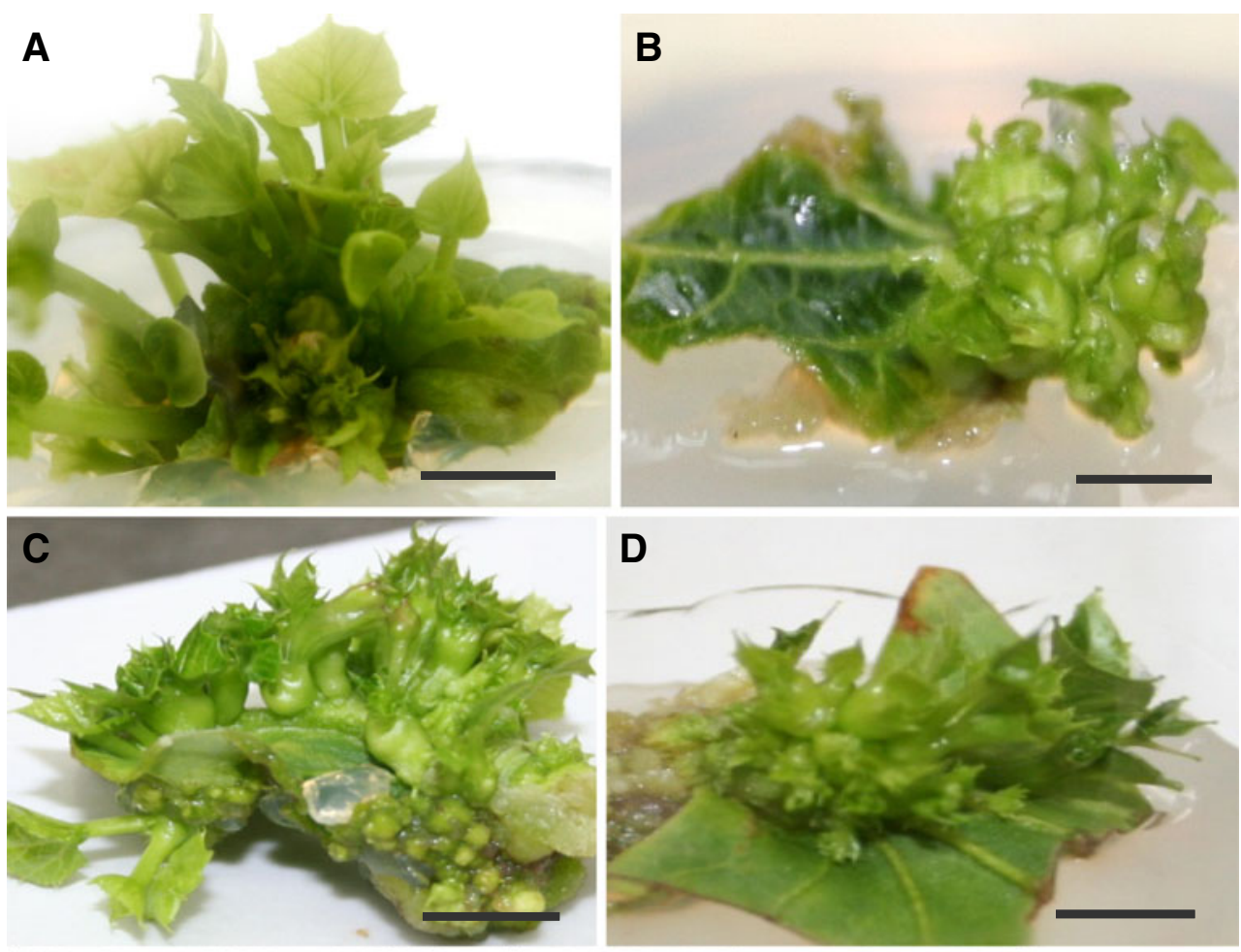

D
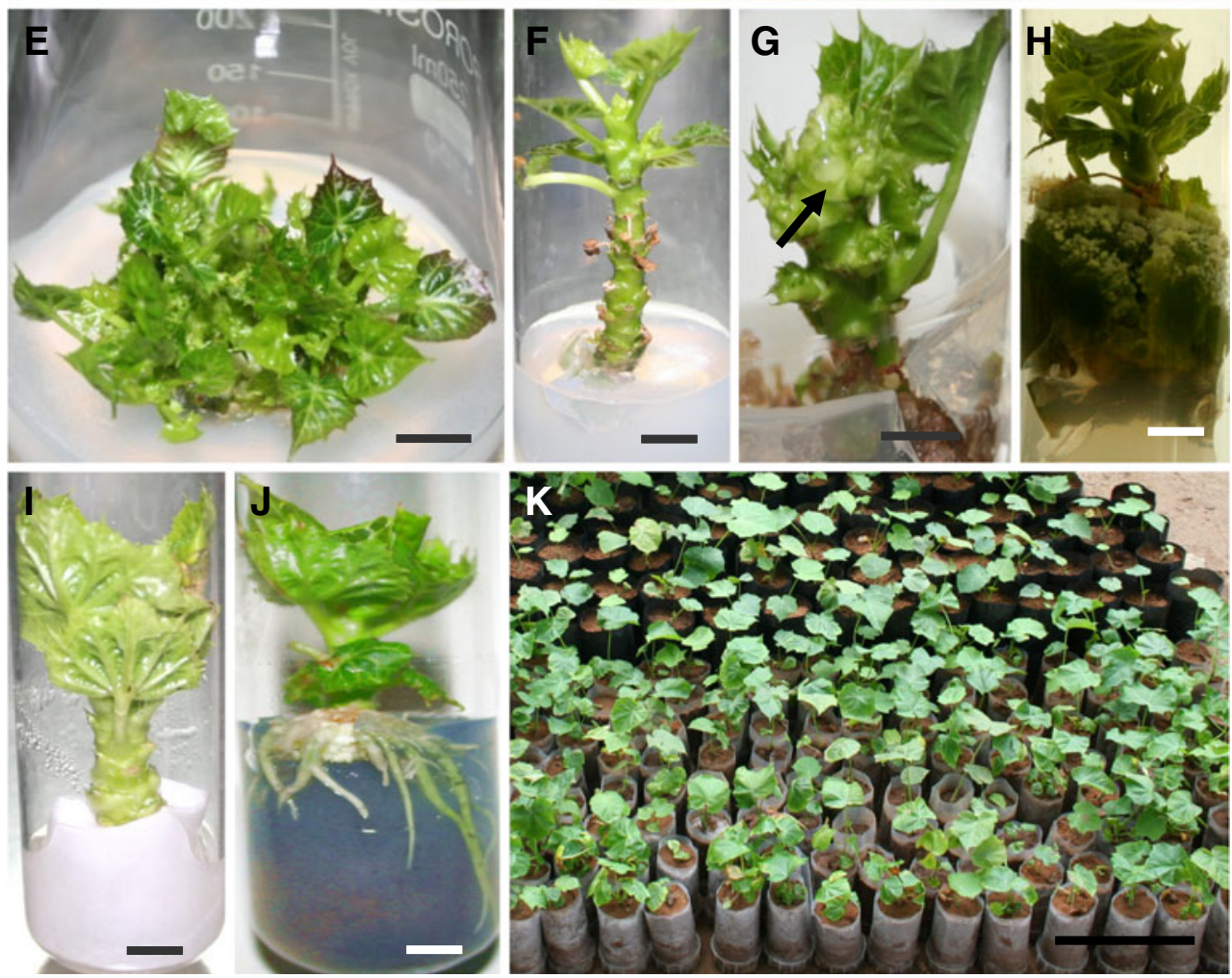

All the experiments were set up in factorial completely randomized design (FCRD) and repeated three times with 25 replicates per treatment and one explant per test tube. Data were subjected to analysis of variance (ANOVA), analyzed by three factor FCRD analysis for regeneration of shoot buds and one factor CRD analysis for shoot elongation and rooting using BASIC software package (Anand Agricultural University, Gujarat, India) at 5\% 
probability level. The results were expressed as mean \pm standard error of three independent experiments.

\section{Results}

Plant growth regulator effects

Plant growth regulator types, concentrations and combinations had significant effects on plant regeneration from leaf explants. The regeneration efficiency was higher in TDZ containing medium as compared to BAP containing medium in term of percent regeneration of shoot buds and the number of shoot buds per explant. When $5 \mu \mathrm{M}$ IBA supplemented in either TDZ or BAP containing medium, regeneration efficiency decreased. Of the different concen- trations of TDZ or BAP tested, individually and in combination with $5 \mu \mathrm{M}$ IBA, the highest percentage of regeneration of shoot bud (81.07\%) and highest number of regenerated shoot buds (20.17) per cotyledonary leaf explant were observed in the presence of $9.08 \mu \mathrm{M}$ TDZ. However, further proliferation and elongation of shoot buds were inhibited due to compact regeneration of shoot buds at this concentration. It was observed that $2.27 \mu \mathrm{M}$ TDZ was the optimum concentration for the regeneration of shoot buds and subsequent sub-culture. At $2.27 \mu \mathrm{M}$ TDZ, the percentage of regeneration of shoot buds varied from $31.22-73.34 \%$ and the number of regenerated shoot buds per explants varied from 2.64-17.13 among the mature and cotyledonary leaf (Tables 1 and 2). Of the different concentrations of BAP tested individually and with $5 \mu \mathrm{M}$ IBA, percentage of regeneration of shoot buds varied from
Table 2 Effect of different plant growth regulators (PGRs), type of explants $(\mathrm{T})$ [mature or cotyledonary leaf] and source (S) [in vitro or field/glasshousegrown] on the number of regeneration of shoot buds per explant of non-toxic $J$. curcas after 6 weeks
BAP, 6-benzylaminopurine; IBA, indole-3-butyric acid TDZ, thidiazuron. Values represent means \pm SE of 25 explants per treatment in three repeated experiments. *Significant at $5 \%$ probability level ( $F$ test). NS, not significant

\begin{tabular}{|c|c|c|c|c|c|c|}
\hline \multirow[t]{2}{*}{ TDZ } & \multirow[t]{2}{*}{ BAP } & \multirow[t]{2}{*}{ IBA } & \multicolumn{2}{|c|}{ Mature leaf expant } & \multicolumn{2}{|c|}{ Cotyledonary leaf explants } \\
\hline & & & In vitro & Field-grown & In vitro & Glasshouse-grown \\
\hline 0.22 & 0 & 0 & $3.11 \pm 0.31$ & $0.89 \pm 0.15$ & $5.01 \pm 1.21$ & $5.00 \pm 1.05$ \\
\hline 0.45 & 0 & 0 & $4.31 \pm 0.66$ & $1.64 \pm 0.27$ & $9.13 \pm 2.36$ & $8.04 \pm 1.20$ \\
\hline 0.90 & 0 & 0 & $4.73 \pm 1.06$ & $1.84 \pm 0.39$ & $13.63 \pm 2.56$ & $12.64 \pm 1.33$ \\
\hline 2.27 & 0 & 0 & $5.23 \pm 1.41$ & $2.64 \pm 0.69$ & $17.13 \pm 1.41$ & $16.61 \pm 1.38$ \\
\hline 4.54 & 0 & 0 & $5.41 \pm 1.43$ & $3.04 \pm 0.95$ & $19.14 \pm 1.43$ & $18.74 \pm 1.55$ \\
\hline 9.08 & 0 & 0 & $5.71 \pm 1.53$ & $3.14 \pm 0.85$ & $20.17 \pm 2.53$ & $19.24 \pm 2.65$ \\
\hline 0.22 & 0 & 5 & $3.01 \pm 0.71$ & $0.75 \pm 0.09$ & $4.81 \pm 1.21$ & $4.75 \pm 1.15$ \\
\hline 0.45 & 0 & 5 & $3.82 \pm 0.81$ & $1.53 \pm 0.21$ & $4.92 \pm 1.31$ & $4.53 \pm 1.31$ \\
\hline 0.90 & 0 & 5 & $4.03 \pm 0.96$ & $1.51 \pm 0.31$ & $5.13 \pm 1.66$ & $5.51 \pm 1.31$ \\
\hline 2.27 & 0 & 5 & $5.03 \pm 1.51$ & $2.43 \pm 0.47$ & $11.53 \pm 2.51$ & $9.93 \pm 1.37$ \\
\hline 4.54 & 0 & 5 & $5.12 \pm 1.83$ & $2.94 \pm 0.86$ & $13.02 \pm 2.83$ & $12.04 \pm 1.56$ \\
\hline 9.08 & 0 & 5 & $5.01 \pm 1.63$ & $3.11 \pm 0.91$ & $14.11 \pm 2.63$ & $13.65 \pm 1.75$ \\
\hline 0 & 13.5 & 0 & $2.09 \pm 0.41$ & $0.65 \pm 0.21$ & $2.76 \pm 0.45$ & $0.67 \pm 0.10$ \\
\hline 0 & 27.0 & 0 & $3.11 \pm 0.73$ & $1.43 \pm 0.69$ & $3.21 \pm 0.63$ & $1.67 \pm 0.39$ \\
\hline 0 & 40.5 & 0 & $3.32 \pm 0.41$ & $1.49 \pm 0.40$ & $3.76 \pm 0.71$ & $1.89 \pm 0.49$ \\
\hline 0 & 54.0 & 0 & $3.99 \pm 0.51$ & $2.03 \pm 0.57$ & $3.95 \pm 0.61$ & $2.83 \pm 0.77$ \\
\hline 0 & 13.5 & 5 & $2.05 \pm 0.31$ & $0.63 \pm 0.15$ & $2.01 \pm 0.81$ & $0.63 \pm 0.09$ \\
\hline 0 & 27.0 & 5 & $3.01 \pm 0.34$ & $1.41 \pm 0.37$ & $3.11 \pm 0.64$ & $1.61 \pm 0.17$ \\
\hline 0 & 40.5 & 5 & $3.21 \pm 0.61$ & $1.47 \pm 0.51$ & $3.67 \pm 0.71$ & $1.77 \pm 0.41$ \\
\hline 0 & 54.0 & 5 & $3.81 \pm 0.81$ & $2.01 \pm 0.55$ & $3.91 \pm 0.81$ & $2.71 \pm 0.65$ \\
\hline \multicolumn{7}{|c|}{ ANOVA summary table } \\
\hline \multicolumn{2}{|c|}{ Source } & df & MS & $\mathrm{F}$ & & \\
\hline \multicolumn{2}{|l|}{ S } & 1 & 11.18 & $9.77 *$ & & \\
\hline \multicolumn{2}{|l|}{$\mathrm{T}$} & 1 & 98.02 & $11.05^{*}$ & & \\
\hline \multicolumn{2}{|l|}{$\mathrm{S} \times \mathrm{T}$} & 1 & 1.68 & $1.01 \mathrm{NS}$ & & \\
\hline \multicolumn{2}{|l|}{ PGRs } & 19 & 67.49 & $24.94 *$ & & \\
\hline \multicolumn{2}{|c|}{$\mathrm{S} \times$ PGRs } & 19 & 0.60 & $0.37 \mathrm{NS}$ & & \\
\hline \multicolumn{2}{|c|}{ T x PGRs } & 19 & 9.45 & $4.54 *$ & & \\
\hline \multicolumn{2}{|c|}{$\mathrm{S} \times \mathrm{T} \times \mathrm{PGRs}$} & 19 & 1.01 & $0.70 \mathrm{NS}$ & & \\
\hline \multicolumn{2}{|l|}{ Error } & 160 & 1.11 & & & \\
\hline \multicolumn{2}{|l|}{ Total } & 239 & & & & \\
\hline
\end{tabular}


$25.11-51.07 \%$, and number of regenerated shoot buds per explants varied from 1.49-3.76 among the mature and cotyledonary leaf in the presence of $54 \mu \mathrm{M}$ of BAP. The percentage of regeneration of shoot buds and the number of shoot buds per leaf explant is directly proportional to the concentration of BAP in both the mature and cotyledonary leaf (Tables 1 and 2).

\section{Explant source effects}

The source of explant also significantly influenced the plant regeneration through direct regeneration of shoot buds at tested concentrations of PGRs in both in vitro and fieldgrown mature leaf explants, in vitro and glasshouse-grown seedlings cotyledonary leaf explants. In vitro mature and cotyledonary leaf explants responded efficiently as compared to field-grown mature and gleasshouse-grown seedlings cotyledonary leaf explants. The percentage of regeneration of shoot buds varied from $13.92-81.07 \%$ in in vitro explants (Table 1, Fig. 1a and c) and 7.02-79.11\% in mature explants (Table 1, Fig. $1 \mathrm{~b}$ and d), and the number of regenerated shoot buds per explant varied from 2.0120.17 in in vitro explants and 0.63-19.24 in mature explants at tested concentrations of PGRs (Table 2).

\section{Explant type effects}

The type of explant also significantly influenced the plant regeneration through direct regeneration of shoot buds at tested concentrations of PGRs in both the mature and cotyledonary leaf. Cotyledonary leaf explants responded efficiently as compared to the mature leaf. The percentage of regeneration of shoot buds varied from $7.02-68.36 \%$ in the mature leaf explants (Table 1, Fig. 1a and b) and 22.12$81.07 \%$ in cotyledonary leaf explants (Table 1, Fig. 1c and d), and the number of regenerated shoot buds per explant varied from $0.63-5.71$ in the mature leaf explants and 0.63-20.17 in cotyledonary leaf explants at tested concentrations of PGRs between both in vitro and glasshousegrown leaf (Table 2).

Shoot proliferation and elongation from regenerated shoot buds

The regenerated shoot buds proliferated on $10 \mu \mathrm{M} \mathrm{Kn}$, 4.5 $\mu \mathrm{M}$ BAP and $5.5 \mu \mathrm{M}$ NAA supplemented medium (Fig. 1e). Individual $(0.3-0.5 \mathrm{~cm})$ shoots were separated from the clump of proliferated shoots and transferred to elongation medium containing different concentrations and combinations of plant growth regulators (PGRs) such as BAP, IAA, NAA and IBA (Table 3). Significant differences in elongation were observed at different concentrations and combinations of PGRs. A combination of BAP and IAA was found to be best and elongation ranged from 2.11$3.01 \mathrm{~cm}$. The best elongation $(3.01 \mathrm{~cm})$ was observed on medium containing $2.25 \mu \mathrm{M}$ BAP and $8.5 \mu \mathrm{M}$ IAA (Table 3, Fig. 1f). Elongation was inhibited on medium containing BAP and IBA. The amount of elongation ranged from $1.94-2.18 \mathrm{~cm}$ on media containing combinations of BAP and IBA, and $2.25 \mu \mathrm{M}$ BAP and $2.5 \mu \mathrm{M}$ IBA gave the
Table 3 Effect of plant growth regulators (PGRs) on elongation of proliferated shoots of nontoxic $J$. curcas after 6 weeks
BAP, 6-benzylaminopurine;

NAA, $\alpha$-naphthaleneacetic acid; IAA, indole 3-acetic acid; IBA, indole-3-butyric acid. Values represent means $\pm \mathrm{SE}$ of 25 proliferated shoots per treatment in three repeated experiments. *Significant at $5 \%$ probability level ( $F$ test)

\begin{tabular}{lcccc}
\hline PGRs $(\mu \mathrm{M})$ & & & & Mean shoot lenght $(\mathrm{cm})$ \\
\hline BAP & IAA & NAA & IBA & \\
\hline 2.25 & 2.8 & 0 & 0 & $2.11 \pm 0.21$ \\
4.5 & 2.8 & 0 & 0 & $2.43 \pm 0.21$ \\
2.25 & 8.5 & 0 & 0 & $3.01 \pm 0.23$ \\
4.5 & 8.5 & 0 & 0 & $2.11 \pm 044$ \\
2.25 & 0 & 2.75 & 0 & $0.91 \pm 0.11$ \\
4.5 & 0 & 2.75 & 0 & $1.21 \pm 0.14$ \\
2.25 & 0 & 8.25 & 0 & $1.71 \pm 0.21$ \\
4.5 & 0 & 8.25 & 0 & $1.01 \pm 0.12$ \\
2.25 & 0 & 0 & 2.5 & $2.18 \pm 0.41$ \\
4.5 & 0 & 0 & 2.5 & $2.08 \pm 0.31$ \\
2.25 & 0 & 0 & 7.5 & $2.11 \pm 0.26$ \\
4.5 & 0 & 0 & 7.5 & $1.94 \pm 0.41$ \\
ANOVA summary & table & & & \\
Source & df & MS & F & \\
PGRs & 11 & 3.02 & $12.61 *$ & \\
Error & 24 & 0.17 & & \\
Total & 35 & & & \\
\hline
\end{tabular}


best elongation $(2.18 \mathrm{~cm})$ (Table 3, Fig. $1 \mathrm{~g})$. Combinations of BAP and NAA promoted the lowest amount of elongation, with the elongation ranging from 0.91$1.71 \mathrm{~cm}$ (Table 3, Fig. 1h).

Rooting and acclimatization

Percentage of rooting significantly differed depending upon the concentrations and combinations of IBA, IAA and NAA. Rooting percentage increased with the increase in the concentration of IBA and also in the presence of IAA and NAA (Table 4). The best rooting percent $(21.71 \%)$ were observed when regenerated elongated shoots were treated with half strength MS liquid medium supplemented with $15 \mu \mathrm{M}$ IBA, $5.7 \mu \mathrm{M}$ IAA and $5.5 \mu \mathrm{M}$ NAA (Fig. 1j). After 6-8 weeks, more than $90 \%$ of plants survived. No morphological abnormalities were observed in regenerated plants (Fig. 1k).

\section{Discussion}

An efficient and reproducible method for the plant regeneration of non-toxic $J$. curcas, plants has been developed. The method employed direct regeneration of shoots from the mature and cotyledonary leaf explants, without the formation of an intervening callus using a MS containing TDZ or BAP individually and in combination with IBA. However, in the present study concentrations, combinations of PGRs in the medium, source and type of explants significantly influenced explants response on regeneration of shoot buds. The PGRs play an important key role in plant morphogenesis. It is reported that TDZ is a potent cytokinin for woody plant tissue culture (Huetteman and Preece 1993). The percentage response of explants forming shoot buds increased with the increase in the concentration of TDZ. Similar observations were made in Hagenia abyssinica (Feyissa et al. 2005), Embellia ribes (Raghu et al. 2006), and J. curcas (Kumar and Reddy 2010; Kumar et al. 2010a). In the present investigation it was observed that low concentrations of TDZ induced relatively fewer shoot buds, but that these developed rapidly into shoots in subsequent culture. In contrast, media containing high concentration of TDZ had more visible primordia but, only a few were able to develop into shoots. The similar results also observed in Miscanthus sinensis (Nielsen et al. 1993 ) and J. curcas (Kumar and Reddy 2010; Kumar et al. 2010a). In Capsicum annuum, $10 \mu \mathrm{M}$ of TDZ induced multiple shoots which failed to elongate (Hyde and Phillips 1996). In the present study it was observed that TDZ was more effective than BAP as cytokinin and the response of explants forming shoot bud decreased after adding the IBA to TDZ or BAP containing medium due to formation of callus. Similar observations were made in Phellodendron amurense (Azad et al. 2005) and J. curcas (Sujatha et al. 2005; Reddy et al. 2008; Misra et al. 2010). Variation in the activity of different cytokinins can be explained by their differential uptake rate reported in different genomes (Kaminek 1992), varied translocation rates to meristematic regions and metabolic processes, in which the cytokinin may be degraded or conjugated with sugars or amino acids to form biologically inert compounds as reported by Kaminek (1992). In vitro explants have more rate and number of regeneration of shoot buds as compared to the
Table 4 Percentage of induction of root on growth regulators free half strength MS medium after four days treatment of the elongated shoot on various concentration and combination of auxins in half strength MS liquid medium of non-toxic J.curcas after 4 weeks

NAA, $\alpha$-naphthaleneacetic acid; IAA, indole 3-acetic acid; IBA, indole-3-butyric acid. Values represent means $\pm \mathrm{SE}$ of 25 regenerated elongated shoots per treatment in three repeated experiments. $*$ Significant at $5 \%$ probability level ( $F$ test)

\begin{tabular}{lccc}
\hline Auxins $(\mu \mathrm{M})$ & \multicolumn{2}{c}{ Rooting induction (\%) } \\
\hline IBA & IAA & NAA & \\
\hline 5 & 0 & 0 & $8.71 \pm 1.01$ \\
10 & 0 & 0 & $9.81 \pm 1.02$ \\
15 & 0 & 0 & $12.78 \pm 1.45$ \\
5 & 5.7 & 5.5 & $11.61 \pm 1.72$ \\
10 & 5.7 & 5.5 & $12.76 \pm 1.62$ \\
15 & 5.7 & 5.5 & $21.71 \pm 1.62$ \\
15 & 11.4 & 5.5 & $11.82 \pm 1.41$ \\
15 & 17.2 & 5.5 & $17.87 \pm 1.44$ \\
15 & 5.7 & 11 & $11.12 \pm 1.52$ \\
15 & 5.7 & 16.5 & F \\
ANOVA summary table & & & $39.87 *$ \\
Source & df & MS & \\
Auxins & 9 & 211.34 & \\
Error & 20 & 4.30 & \\
Total & 29 & & \\
\hline
\end{tabular}


mature and cotyledonary leaf explants. This may be due to level of endogenous hormones. Similar results were observed (Ozaslan et al. 2005; Reddy et al. 2008; Kumar and Reddy 2010; Kumar et al. 2010a). Explant type is one of the most important factors affecting regeneration (Shen et al. 2008). In our study, both the mature and cotyledonary leaf explants showed differences in the percentage of regeneration of shoot bud, number of shoot buds per explants. This may be due to differences in the levels of endogenous hormones, particularly cytokinins levels during the regeneration period (Preece and Imel 1991). The inhibitory effect of high concentration of TDZ on shoot elongation has been reported by many researchers, who recommend that the TDZ concentration must be reduced and/or other cytokinins or combinations of cytokinins and auxins must be used for further shoot elongation (Preece and Imel 1991; Huetteman and Preece 1993; Feyissa et al. 2005) and our results are in agreement with above findings. Following the transfer of proliferated shoots to the elongation medium, the elongation of individual shoots depended upon the concentrations and combinations of PGRs in the medium. The maximum elongation was obtained using combinations of BAP and IAA as compared to BAP and IBA, and BAP and NAA. Our results are consistent with the previous (Christopher and Rajam 1996; Venkataiah and Subhash 2003) observations. Elongation was reduced in the medium containing BAP and IBA, which may be due to the proliferation of axillary buds. A similar observation has been reported in Eupatorium triplinerve (Martin 2003). The low elongation observed in a medium containing BAP and NAA may be due to the profuse callusing at the basal end of proliferated shoots (Kumar et al. 2008). The percentage of rooting was directly proportional to the concentration of IBA and a higher percentage was observed in combinations of auxins as compared to IBA alone. Similar observations have been observed in Simmondsia chinensis (Singh et al. 2008) and J. curcas (Kumar and Reddy 2010; Kumar et al. 2010c). The acclimatization of the rooted shoots was easily accomplished and more than $90 \%$ of the plants were successfully transferred to polythene bags in under greenhouse conditions. In conclusion this is the first report on plant regeneration through direct organogenesis from leaf explants of non-toxic $J$. curcas, which may be useful for mass propagation and genetic transformation.

Acknowledgements The authors gratefully acknowledge Council of Scientific and Industrial Research, New Delhi for financial assistance and Prof. K. Becker, Department of Aquaculture Systems and Animal Nutrition, University of Hohenheim, Stuttgart, Germany for providing Mexican non-toxic J. curcas seeds. Statistical data analysis support from Dr. Keyur Shah and Dr. Amritpal Singh, Assistant professor, Anand Agricultural University, Anand is thankfully acknowledged.

\section{References}

Azad MAK, Yokota S, Ohkubo T, Andoh Y, Yahara S, Yoshizawa N (2005) In vitro regeneration of the medicinal woody plant Phellodendron amurense Rupr. Through excised leaves. Plant Cell Tissue Organ Cult 80:43-50

Christopher T, Rajam MV (1996) Effect of genotype, explant and medium on in vitro regeneration of red pepper. Plant Cell Tissue Organ Cult 46:245-250

da Camara Machado A, Frick NS, Kremen R, Katinger H, da Camara Machado ML (1997) Biotechnological approaches to the improvement of Jatropha curcas. In Proceedings of the International Symposium on Jatropha,. Managua, Nicaragua, Mexico, pp. 15

Deore AC, Johnson TS (2008) High-frequency plant regeneration from leaf-disc cultures of Jatropha curcas L.: an important biodiesel plant. Plant Biotech Rep 2:10-15

Feyissa T, Welander M, Negash L (2005) In vitro regeneration of Hagenia abyssinica (Bruce) J.F. Gmel. (Rosaceae) from leaf explants. Plant Cell Rep 24:392-400

Huetteman CA, Preece JE (1993) Thidiazuron: a potent cytokinin for woody plant tissue culture. Plant Cell Tissue Organ Cult 33:105-119

Hyde CL, Phillips GC (1996) Silvernitrate promotes shootdevelopment and plant regeneration of Chilepepper (Capsicum annuum L.) via organogenesis. In Vitro Cell Dev Biol Plant 32:72-80

Jha T, Mukherjee P, Datta MM (2007) Somatic embryogenesis in Jatropha curcas Linn. an important biofuel plant. Plant Biotech Rep 1:135-140

Kaminek M (1992) Progress in cytokinin research. Trends Biotech 10:159-162

Kumar N (2008) Studies on regeneration and genetic transformation of Jatropha curcus. Phd Thesis, Bhavnagar University, Bhavnagar, India

Kumar N, Reddy MP (2010) Plant regeneration through the direct induction of shoot buds from petiole explants of Jatropha curcas: a biofuel plant. Ann Appl Biol 156:367-375

Kumar N, Pamidimarri SDVN, Kaur M, Boricha M, Reddy MP (2008) Effects of $\mathrm{NaCl}$ on growth, ion accumulation, protein, proline contents, and antioxidant enzymes activity in callus cultures of Jatropha curcas. Biologia 63:378-382

Kumar N, Vijayanand KG, Reddy MP (2010a) Shoot regeneration from cotyledonary leaf explants of Jatropha curcas: a biodesel plant. Acta Physiol Plant 32:917-924

Kumar N, Vijayanand KG, Reddy MP (2010b) In vitro plant regeneration of non-toxic Jatropha curcas L: direct shoot organogenesis from cotyledonary petiole explants. J Crop Sci Biotech 13:189-194

Kumar N, Vijayanand KG, Pamidimarri DVNS, Sarkar T, Reddy MP, Radhakrishnan T, Kaul T, Reddy MK, Sapori SK (2010c) Stable genetic transformation of Jatropha curcas via Agrobacterium tumefaciens-mediated gene transfer using leaf explants. Ind Crop Prod 32:41-47

Kumar N, Vijayanand KG, Reddy MP (2011) In vitro regeneration from petiole explants of non-toxic Jatropha curcas. Ind Crops Prod 33:146-151

Makkar HPS, Becker K (1997) Potential of Jatropha seed cake as protein supplement in livestock feed and constraints to its utilization. In Proceedings of Jatropha: International symposium on Biofueland Industrial Products from Jatropha curcas and otherTropical Oil Seed Plants. Nicaragua, Mexico, pp. 2327

Makkar HPS, Aderibigbe AO, Becker K (1998) Comparative evaluation of non-toxic and toxic varieties of Jatropha curcas for chemical composition, digestibility, protein degradability and toxic factors. Food Chem 62:207-215 
Martin KP (2003) Rapid axillary bud Proliferation and ex vitro rooting of Eupatorium triplinerve. Biol Plant 47:589-591

Misra P, Gupta N, Toppo DD, Pandey V, Mishra MK, Tuli R (2010) Establishment of long-term proliferating shoot cultures of elite Jatropha curcas L. by controlling endophytic bacterial contamination. Plant Cell Tissue Organ Cult 100:189-197

Murashige T, Skoog F (1962) A revised medium for rapid growth and bioassays with tobacco tissue cultures. Physiol Plant 15:473-479

Nielsen JM, Kirsten B, Hansen J (1993) Long-term effects of thidiazuron are intermediate between Benzyladenine, kinetin or isopentenyladenine in Miscanthus sinensis. Plant Cell Tissue Organ Cult 35:173-179

Ozaslan M, Can C, Aytekin T (2005) Effect of explant source on in vitro propagation of Paulownia tomentosa Steud. Biotech Biotech Equip 19:20-26

Preece JE, Imel MR (1991) Plant regeneration from leaf explants of Rhododendron 'P.J.M. Hybrids'. Sci Hort 48:159-170

Raghu AV, Geetha SP, Martin G, Balachandran I, Ravindran PN (2006) Direct organogenesis from leaf explants of Embelia ribes Burm. -a vulnerable medicinal plant. J For Res 11:57-60

Rajore S, Batra A (2007) An alternative source for regenerable organogenic callus induction in Jatropha curcas. Indian J Biotechnol 6:545-548
Reddy MP, Kumar N, Vijayanand KG, Singh AH, Singh S (2008) Method for micropropagation of Jatropha curcas plants from leaf explants. (Patent filed US and PCT, File No.0088NF2008).

Shen X, Kane ME, Chen J (2008) Effects of genotype, explants source, and plant growth regulators on indirect shoot organogenesis in Dieffenbachia cultivars. In Vitro Cell Dev Bio Plant 44:282-288

Singh A, Reddy MP, Patolia JS (2008) An improved protocol for micropropagation of elite genotypes of Simmondsia chinensis (Link) Schneider. Biol Plant 52:538-540

Sujatha M, Mukta N (1996) Morphogenesis and plant regeneration from tissue cultures of Jatropha curcas. Plant Cell Tissue Organ Cult 44:135-141

Sujatha M, Makkar HPS, Becker K (2005) Shoot bud proliferation from axillary nodes and leaf sections of non-toxic Jatropha curcas L. Plant Growth Regul 47:83-90

Takeda Y (1982) Development study on Jatropha curcas (sabudum) oil as a substitute for diesel engine oil in Thailand. J Agr Assoc China 120:1-8

Venkataiah P, Subhash K (2003) Thidiazuron-induced adventitious shoot bud formation and plant regeneration in Capsicum annuum L. J Plant Biotechnol 5:245-250 